\title{
Deprotonation of C-Alkyl Groups of Cationic Triruthenium Clusters Containing Cyclometalated C-Alkylpyrazinium Ligands: Experimental and Computational Studies
}

\author{
Javier A. Cabeza, ${ }^{[\mathrm{a}]}$ José M. Fernández-Colinas, ${ }^{[\mathrm{a}]}$ Pablo García-Álvarez, ${ }^{[\mathrm{a}]}$ Enrique Pérez- \\ Carreño,${ }^{[\mathrm{b}]}$ Vanessa Pruneda, ${ }^{[\mathrm{a}]}$ and Juan F. Van der Maelen ${ }^{[\mathrm{b}]}$
}

\begin{abstract}
The C-alkyl groups of cationic triruthenium cluster complexes of the type $\left[\mathrm{Ru}_{3}(\mu-\mathrm{H})\left(\mu-\kappa^{2} N^{1}, C^{2}-\mathrm{L}\right)(\mathrm{CO})_{10}\right]^{+} \quad(\mathrm{HL}$ represents a generic C-alkyl-Nmethylpyrazium) have been deprotonated to give kinetic products that contain unprecedented $\mathrm{C}$-alkylidene derivatives and maintain the original edge-bridged decacarbonyl structure. When the starting complexes contain various C-alkyl groups, the selectivity of these deprotonation reactions is related to the atomic charges of the alkyl $\mathrm{H}$ atoms (as suggested by DFTNBO calculations). Three additional electronic properties of the $\mathrm{C}$-alkyl $\mathrm{C}-\mathrm{H}$ bonds have also been found to correlate with the experimental regioselectivity, since,
\end{abstract}

in all cases, the deprotonated $\mathrm{C}-\mathrm{H}$ bond is that having the smallest electron density at the bond critical point, the greatest Laplacian of the electron density at the bond critical point, and the greatest total energy density ratio at the bond critical point (QTAIM calculations). The kinetic decacarbonyl products evolve, under appropriate reaction conditions that depend upon the position of the $\mathrm{C}$-alkylidene group in the heterocyclic ring, toward face-capped nonacarbonyl derivatives (thermodynamic products). The position of the C-alkylidene group in the heterocyclic ring determines the distribution of single and double bonds within the ligand ring and this strongly affects the stability of the neutral decacarbonyl complexes and the way these ligands coordinate to the metal atoms in the nonacarbonyl products. The mechanisms of these decacarbonylation processes have been investigated by DFT methods, which have rationalized the structures observed for the final products and have shed light on the different kinetic and thermodynamic stabilities of the reaction intermediates, explaining the reaction conditions experimentally required by each transformation.

Keywords: C-H deprotonation • cationic ligands $\cdot \mathrm{N}$-ligands pyrazinium ligands $\cdot \mathrm{C}-\mathrm{H}$ activation

\section{Introduction}

Metal complexes containing cationic ligands derived from aromatic six-membered-ring N-heterocycles can be classified in two broad groups according to the atom through which the ligand is attached to the metal: a) those having a C-metalated "inium" ligand and b) those containing an N-metalated "inium" ligand. The first group comprises mono- ${ }^{[1-3]}$ and trinuclear ${ }^{[4]}$ complexes that generally derive from $\mathrm{N}$-substituted pyridines ${ }^{[1,2,4]}$ or other one- $\mathrm{N}^{[1,2,4]}$ or two- $\mathrm{N}^{[3]}$ heterocycles, but their ligands are best described as neutral N-heterocyclic carbenes (Figure 1, A). The complexes of the second group are mostly mononuclear, they

[a] Prof. J. A. Cabeza, Dr. J. M. Fernández-Colinas, Dr. P. GarcíaÁlvarez, Dr. V. Pruneda

Departamento de Química Orgánica e Inorgánica-IUQOEM Universidad de Oviedo-CSIC, E-33071 Oviedo (Spain)

Fax: (+) 34-985103446

E-mail: jac@uniov.es

[b] Dr. E. Pérez-Carreño, Dr. J. F. Van der Maelen Departamento de Química Física y Analítica Universidad de Oviedo, E-33071 Oviedo (Spain)

Supporting information for this article is available on the WWW under http://dx.doi.org/10.1002/chem.201204250. contain an N-substituted N'-coordinated two-N heterocycle, and are well represented in the literature, ${ }^{[5,6]}$ particularly for $\mathrm{N}$ methylpyrazinium, which is a very strong $\pi$-acceptor ligand (Figure 1, B). A few reports dealing with their one-electronreduction to mononuclear radical derivatives have been published ${ }^{[6]}$ but ligand deprotonation processes have not been hitherto reported.

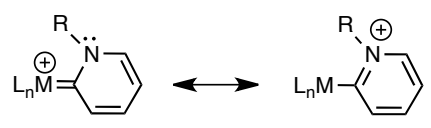

(A)
(B)

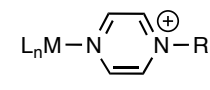

Figure 1. "Carbene" and "inium" resonance structures of a C-metalated pyridinium (A) and an N-metalated pyrazinium (B) in cationic metal complexes.

Complexes that can concurrently be ascribed to both groups (a and $\mathrm{b}$ ), i.e., those derived from $\mathrm{C}$ - and $\mathrm{N}$-metalated "inium" cations, were unknown before the recent description of the cationic triruthenium derivatives $\left[\mathrm{Ru}_{3}(\mu-\mathrm{H})\left(\mu-\kappa^{2} N, C-\mathrm{L}\right)(\mathrm{CO})_{10}\right]^{+}$, $\mathrm{HL}=\mathrm{N}$-methylquinoxalinium, ${ }^{[7]} \mathrm{N}$-methylpyrazinium, ${ }^{[7]} \mathrm{N}$ methylpyrimidinium, ${ }^{[8]}$ 1,2-dimethylpyrimidinium, ${ }^{[9]}$ and 1 methyl-1,5-naphthyridinium. ${ }^{[10]}$ The cationic ligands of these triruthenium clusters are readily attacked by anionic nucleophiles at selected $\mathrm{C}$ atoms of their ligand rings (some examples are 
depicted in Scheme 1), ${ }^{[7-9]}$ and are also prone to undergo oneelectron-reduction processes that lead to dimeric hexanuclear products. ${ }^{[8-10]}$ These nucleophilic attacks and reduction reactions are orbital-controlled rather than charge-controlled processes and lead to neutral complexes with unsaturated but nonaromatic Nheterocyclic ligands that in some cases are N-heterocyclic carbenes (Scheme 1).

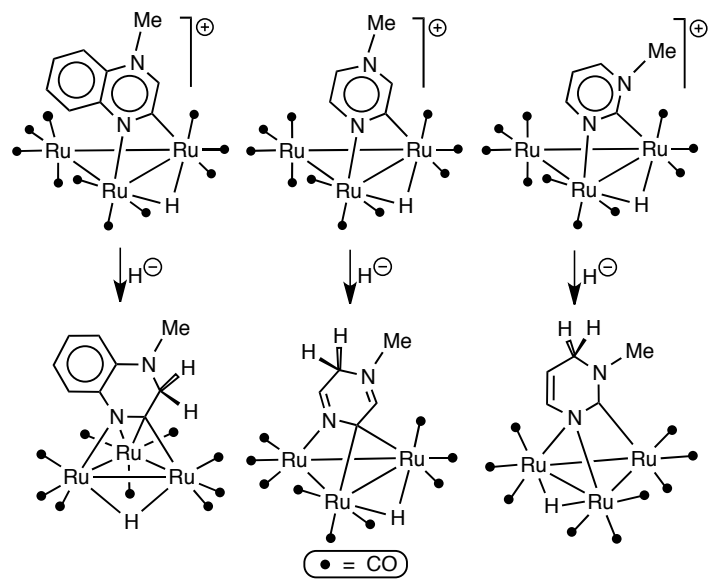

Scheme 1. Nucleophilic addition of a hydride to cationic triruthenium clusters derived from $\mathrm{N}$-methylquinoxalinium (left) ${ }^{[7]} \mathrm{N}$-methylpyrazinium (center) ${ }^{[7]}$ and $\mathrm{N}$-methylpyrimidinium (right). ${ }^{[8]}$

This paper reports that the alkyl groups of triruthenium clusters containing $\mathrm{C}$-alkylpyrazimium-derived ligands can be selectively deprotonated to give neutral products that contain novel C-alkylidenepyrazine-derived ligands. ${ }^{[1]}$ Theoretical studies (DFT-NBO atomic charges and QTAIM analysis of the electron density) have been used to rationalize the regioselectivity of deprotonation reactions of starting materials containing various $\mathrm{C}$-alkyl groups on different positions of the pyrazine ring. DFT analysis of potential energy surfaces has been used to shed light on the mechanisms of observed decarbonylation processes, including that of an unexpected and very interesting transformation of a decacarbonyl complex having a methylidene group on the $\mathrm{C}^{3}$ carbon atom of the pyrazine ring into a derivative that formally has that methylidene group on the $\mathrm{C}^{5}$ carbon atom of the pyrazine ring.

C-Alkyl deprotonation is unprecedented for Calkylpyrazinium metal complexes. Although it has been observed for metal-free C-alkylpyrazinium cations, ${ }^{[12,13]}$ the corresponding deprotonated products, which are useful intermediates in heterocyclic syntheses, ${ }^{[12]}$ are not stable enough to be isolated.

\section{Results and Discussion}

Synthesis of the cationic cluster precursors: The cationic Calkylated triruthenium clusters used in this work (compounds $\mathbf{1 b}$ $\mathbf{5 b}$, Scheme 2) were prepared from $\left[\mathrm{Ru}_{3}(\mathrm{CO})_{12}\right]$, the corresponding $\mathrm{C}$-alkylpyrazine, and methyl triflate, following the synthetic procedure previously used to prepare $\left[\operatorname{Ru}_{3}(\mu-\mathrm{H})(\mu-\right.$ $\left.\left.\kappa^{2} N, C-\mathrm{L}\right)(\mathrm{CO})_{10}\right]$ OTf $\left(\mathrm{HL}=\mathrm{N}\right.$-methylquinoxalinium). ${ }^{[7]}$ The experimental details of these reactions and the spectroscopic and other analytical data of their products are given in the Supporting Information.

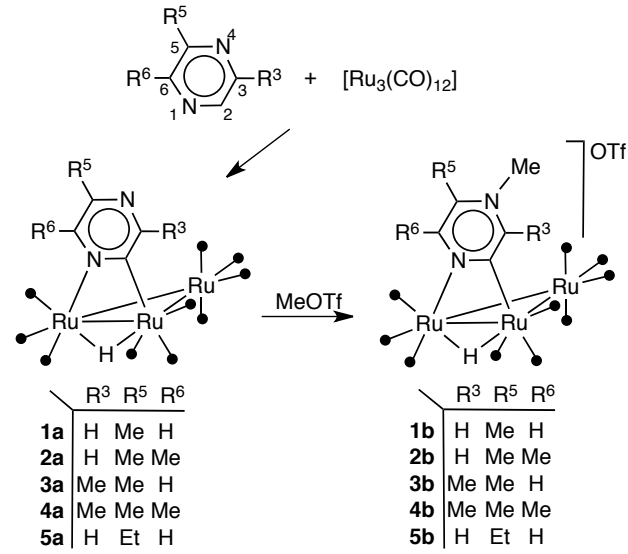

Scheme 2. Synthesis of compounds $\mathbf{1 b}-\mathbf{5 b}$. The labeling scheme used for the heterocyclic ring atoms and alkyl substituents is also shown.

C-Alkyl deprotonation of the cationic cluster precursors: The reactions of compounds $\mathbf{1 b}, \mathbf{2} \mathbf{b}, \mathbf{4 b}$, and $\mathbf{5 b}$ with $\mathrm{K}\left[\mathrm{N}\left(\mathrm{SiMe}_{3}\right)_{2}\right]$ proceeded quickly in THF at room temperature to give the respective $\mathrm{C}^{5}$-alkylidene nonacarbonyl derivatives $1 \mathbf{c}, \mathbf{2 c}, \mathbf{4 c}$, and 5c (Scheme 3), as major components of reaction mixtures that also contained small amounts of the N-demethylated clusters 1a, 2a, 4a, or 5a, respectively. All these reaction products were satisfactorily separated by chromatographic techniques and were characterized by spectroscopic and analytical methods, and, in the case of compounds $\mathbf{2 c}$ and $\mathbf{4 c}$ (Figure 2), also by X-ray diffraction.

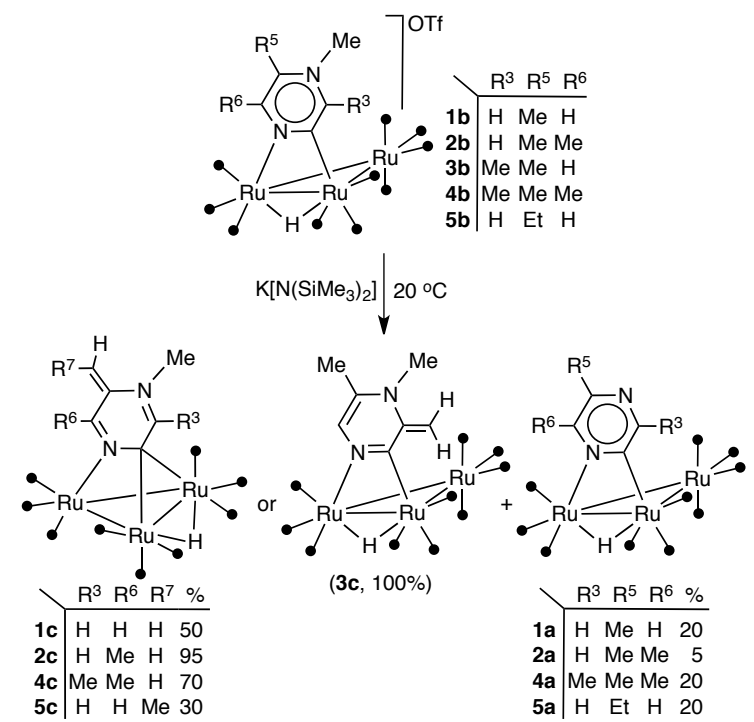

Scheme 3. Reactions of compounds $\mathbf{1 b}-\mathbf{5} \mathbf{b}$ with $\mathrm{K}\left[\mathrm{N}\left(\mathrm{SiMe}_{3}\right)_{2}\right]$. The yields given were estimated by ${ }^{1} \mathrm{H}$ NMR integration of the spectra of aliquots taken from the crude reaction mixtures after consumption of the starting cationic cluster.

All the $\mathrm{C}^{5}$-alkylidene derivatives have a common IR $v(\mathrm{CO})$ pattern and a hydride NMR resonance at $c a$. $-14.0 \mathrm{ppm}$, confirming that they all have an analogous molecular structure. Their +FAB mass spectra are also in agreement with their nonacarbonyl structures. The stereochemistry of the ethylidene group of compound $\mathbf{5} \mathbf{c}$ was established by $\mathrm{NOE}{ }^{1} \mathrm{H} \mathrm{NMR}$, which clearly indicated that the $\mathrm{N}-\mathrm{Me}$ group is closer to the $\mathrm{C}=\mathrm{CH}$ proton than to the $\mathrm{C}=\mathrm{CMe}$ protons, which, in turn, are in the vicinity of the $\mathrm{C}^{6}-\mathrm{H}$ ring proton (Figure $\mathrm{S} 4$ of Supporting Information). 


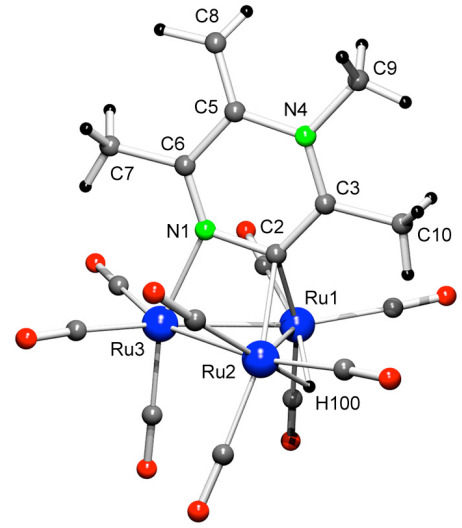

Figure 2. Molecular structure of 4c. Selected bond distances $(\AA)$ : Ru1-Ru2 2.7816(3), Ru1-Ru3 2.7471(3), Ru2-Ru3 2.7493(3), Ru1-C2 2.190(3), Ru2-C2 2.199(3), Ru3-N1 2.117(3), C2-N1 1.432(4), C2-C3 1.406(4), C3-C10 1.487(5), C3-N4 1.337(4), N4-C5 1.416(6), N4-C9 1.479(5), C5-C6 1.454(6), C5-C8 1.339(7), C6-C7 1.498(5), C6-N1 1.293(4). This structure is essentially analogous to that of 2c (Supporting Information), except that the latter has a hydrogen atom on the $\mathrm{C} 3$ carbon atom.

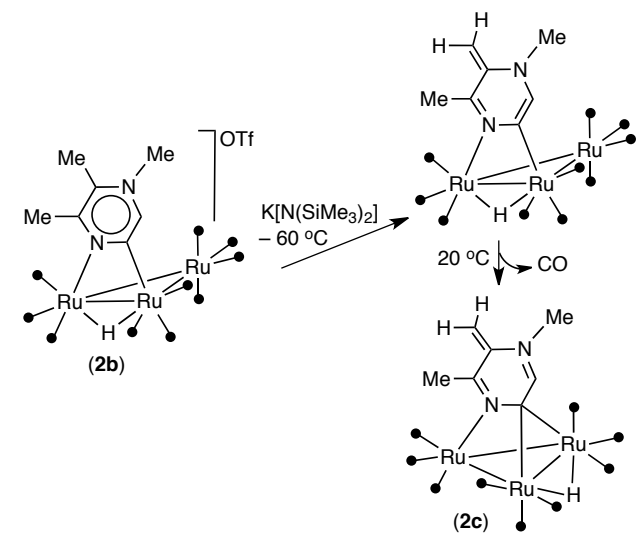

Scheme 4. Experimentally observed steps of the transformation of $\mathbf{2 b}$ into $\mathbf{2 c}$

In order to obtain experimental mechanistic information on these deprotonation reactions, a THF- $d_{8}$ solution of compound $\mathbf{2} \mathbf{b}$, taken as a representative example, was treated with $\mathrm{K}\left[\mathrm{N}\left(\mathrm{SiMe}_{3}\right)_{2}\right]$ at $-60{ }^{\circ} \mathrm{C}$. The ${ }^{1} \mathrm{H}$ NMR spectrum of this solution (maintained at $60{ }^{\circ} \mathrm{C}$ ) showed the formation of a new species characterized by a hydride resonance at $-14.52 \mathrm{ppm}$ that also contained a $\mathrm{C}=\mathrm{CH}_{2}$ group. The chemical shift of that hydride resonance is comparable to those of compounds $\mathbf{1 a - 5 a}$, which are neutral decacarbonyl edge-doubly-bridged clusters. This species could not be isolated because it evolved to compound $\mathbf{2 c}$ as soon as the solution was warmed up. These data indicate that the deprotonation process should have a very low activation barrier (it is very fast even at $60{ }^{\circ} \mathrm{C}$ ) and that the neutral C-methylidene derivative spontaneously decarbonylates (with a higher but still low energy barrier) to give the nonacarbonyl derivative 2c (Scheme 4).

Curiously, the treatment of compound $\mathbf{3 b}$ with $\mathrm{K}\left[\mathrm{N}\left(\mathrm{SiMe}_{3}\right)_{2}\right]$ at room temperature did not afford a $\mathrm{C}^{5}$-methylidene nonacarbonyl product but the $\mathrm{C}^{3}$-methylidene decacarbonyl derivative 3c in quantitative yield (Scheme 3). This compound was stable in solution at room temperature for a few hours. Its ligand-edge-bridged decacarbonyl structure was confirmed by its $+\mathrm{FAB}$ mass spectrum, which contains the corresponding molecular ion isotopomeric peaks, its ${ }^{13} \mathrm{C}-\mathrm{NMR}$ spectrum, which shows ten resonances in the CO ligand region, and its IR spectrum, whose $v(\mathrm{CO})$ absorptions are nearly identical to those of $\mathbf{3 a}$. The location of the methylidene group on the $\mathrm{C}^{3}$ atom was established by $\mathrm{NOE}{ }^{1} \mathrm{H}$ NMR, which confirmed that the ring $\mathrm{C}-\mathrm{H}$ proton is close to the $\mathrm{C}-\mathrm{Me}$ methyl group and far away from the $\mathrm{C}=\mathrm{CH}_{2}$ protons (Figure S2 of Supporting Information).

The C-methyl group of the cationic pyrimidine-derived complex $\left[\mathrm{Ru}_{3}(\mu-\mathrm{H})\left(\mu-\kappa^{2} N, C-\text { pyrMe } 2\right)(\mathrm{CO})_{10}\right]^{+}\left(\mathrm{HpyrMe}_{2}=1,2-\right.$ dimethylpyrimidinium) can also be deprotonated with a strong base. ${ }^{[9]}$ That reaction is the only previously reported deprotonation related to those described in this paper.

We were surprised by the unique reactivity of compound $\mathbf{3 b}$ (in comparison with the remaining reactions shown in Scheme 3), founding the different reactivities of $\mathbf{3 b}$ and $\mathbf{4 b}$ particularly intriguing because both compounds have methyl substituents at either sides $\left(\mathrm{C}^{3}\right.$ and $\mathrm{C}^{5}$ positions) of the $\mathrm{N}-\mathrm{Me}$ group, differing only by the absence (3b) or presence (4b) of a methyl group on the ring $\mathrm{C}^{6}$ carbon atom. These different reactivities imply a) a different regioselectivity of the deprotonation processes, i.e., deprotonation of the $\mathrm{C}^{3}-\mathrm{Me}$ group of $\mathbf{3 b}$ but deprotonation of the $\mathrm{C}^{5}-\mathrm{Me}$ group of $\mathbf{4 b}$, and b) a different stability of the deprotonated decacarbonyl products, since that arising from $\mathbf{3 b}$ is stable at room temperature (compound 3c, Scheme 3) whereas that arising from $\mathbf{4 b}$ is unstable under similar conditions, evolving toward the observed nonacarbonyl product $\mathbf{4 c}$ (Scheme 3). These reactivity issues are addressed in the following sections of this manuscript.
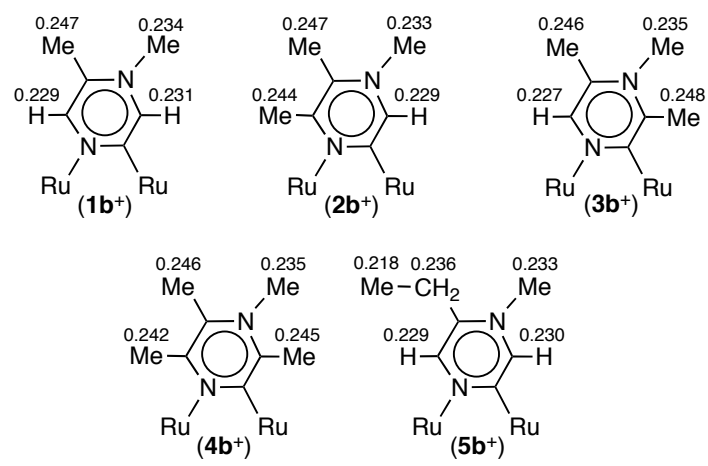

Figure 3. NBO atomic charges, calculated at the B3P86/WTBS/6-311++G(3df,3pd) level of theory, of the ligand $\mathrm{H}$ atoms (averaged values in the cases of $\mathrm{CH}_{3}$ and $\mathrm{CH}_{2}$ groups) in the cations $\mathbf{1} \mathbf{b}^{+}-\mathbf{5} \mathbf{b}^{+}$(for clarity, only the heterocyclic ligand and two Ru atoms of each cluster cation are shown).

Theoretical approaches to the regioselectivity of the deprotonation reactions: With the aim of rationalizing the regioselectivity of the deprotonation processes that lead to the Calkylidene compounds $\mathbf{1 c}-\mathbf{5 c}$, we first calculated the natural bond orbital $(\mathrm{NBO})^{[14]}$ atomic charges of the ligand $\mathrm{H}$ atoms of the cations $\mathbf{1} \mathbf{b}^{+}-\mathbf{5} \mathbf{b}^{+}$, reasoning that the higher the atomic charge of a hydrogen atom the easier its deprotonation would be. The results shown in Figure 3, computed at a very high level of theory, B3P86/WTBS/6-311++G(3df,3pd), indicate that the greatest hydrogen atomic charges are located on the $\mathrm{C}^{3}-\mathrm{Me}$ hydrogen atoms for $\mathbf{3 b}^{+}$but on the $\mathrm{C}^{5}-\mathrm{CH}_{2} \mathrm{R}$ hydrogen atoms for the remaining cationic compounds $\left(\mathrm{R}=\mathrm{H}\right.$ in $\mathbf{1} \mathbf{b}^{+}, \mathbf{2} \mathbf{b}^{+}$, and $\mathbf{4} \mathbf{b}^{+} ; \mathrm{R}=$ Me in $\mathbf{5} \mathbf{b}^{+}$). From these data, it can be inferred that the presence of a methyl group in the ligand ring results in a decrease of the atomic charge of the $\mathrm{H}$ atoms of the group $(\mathrm{H}$ or $\mathrm{Me})$ situated in its para position. This accounts for the greater charge of the 
Table 1. QTAIM topological parameters for the C-H bonds of $\mathbf{1 b}^{+}-\mathbf{5} \mathbf{b}^{+}$, calculated at the B3P86/WTBS/6-311++G(3df,3pd) level of theory.

\begin{tabular}{|c|c|c|c|c|c|c|c|}
\hline Cluster & Bond & $d[\AA]^{[c]}$ & $\rho_{\mathrm{b}}\left[\mathrm{e} \AA^{-3}\right]^{[d]}$ & $\nabla^{2} \rho_{\mathrm{b}}\left[\mathrm{e} \AA^{-5}\right]^{[e]}$ & $H_{\mathrm{b}} / \rho_{\mathrm{b}}\left[\mathrm{h} \mathrm{e}^{-1}\right]^{[f]}$ & $G_{\mathrm{b}} / \rho_{\mathrm{b}}\left[\mathrm{h} \mathrm{e}^{-1}\right]^{[g]}$ & $\varepsilon_{\mathrm{b}}{ }^{[h]}$ \\
\hline \multirow[t]{4}{*}{$\mathbf{1 b}^{+}$} & $\mathrm{C}^{3}-\mathrm{H}$ & 1.081 & 2.006 & -27.306 & -1.075 & 0.122 & 0.030 \\
\hline & $\mathrm{C}^{5} \mathrm{C}-\mathrm{H}_{\mathrm{Me}}{ }^{[a]}$ & 1.092 & $\underline{1.893}$ & -23.849 & -1.040 & 0.158 & 0.013 \\
\hline & $\mathrm{C}^{6}-\mathrm{H}$ & 1.083 & 1.998 & -27.087 & -1.071 & 0.121 & 0.028 \\
\hline & $\mathrm{N}^{4} \mathrm{C}-\mathrm{H}_{\mathrm{Me}}{ }^{[a]}$ & 1.089 & 1.949 & -25.472 & -1.052 & 0.137 & 0.033 \\
\hline \multirow[t]{4}{*}{$\overline{2 \mathbf{b}^{+}}$} & $\mathrm{C}^{3}-\mathrm{H}$ & 1.080 & 2.007 & -27.260 & -1.076 & 0.125 & 0.033 \\
\hline & $\mathrm{C}^{5} \mathrm{C}-\mathrm{H}_{\mathrm{Me}}{ }^{[a]}$ & 1.091 & $\underline{1.898}$ & -23.947 & -1.043 & 0.160 & 0.014 \\
\hline & $\mathrm{C}^{6} \mathrm{C}-\mathrm{H}_{\mathrm{Me}}^{[a]}$ & 1.090 & 1.900 & -23.987 & -1.045 & 0.161 & 0.013 \\
\hline & $\mathrm{N}^{4} \mathrm{C}-\mathrm{H}_{\mathrm{Me}}{ }^{[a]}$ & 1.088 & 1.950 & -25.495 & -1.053 & 0.138 & 0.033 \\
\hline \multirow[t]{4}{*}{$\mathbf{3 b}^{+}$} & $\mathrm{C}^{3} \mathrm{C}-\mathrm{H}_{\mathrm{Me}}{ }^{\lfloor a\rfloor}$ & 1.091 & 1.895 & -23.821 & -1.040 & 0.160 & 0.013 \\
\hline & $\mathrm{C}^{5} \mathrm{C}-\mathrm{H}_{\mathrm{Me}}{ }^{[a]}$ & 1.092 & 1.895 & -23.929 & $\overline{-1.042}$ & 0.158 & 0.013 \\
\hline & $\mathrm{C}^{6}-\mathrm{H}$ & 1.082 & 1.999 & -27.048 & -1.072 & 0.125 & 0.030 \\
\hline & $\mathrm{N}^{4} \mathrm{C}-\mathrm{H}_{\mathrm{Me}}{ }^{[a]}$ & 1.087 & 1.956 & -25.606 & -1.056 & 0.140 & 0.034 \\
\hline \multirow[t]{4}{*}{$\overline{4 b^{+}}$} & $\mathrm{C}^{3} \mathrm{C}-\mathrm{H}_{\mathrm{Me}}{ }^{\lfloor a\rfloor}$ & 1.090 & 1.903 & -24.052 & -1.046 & 0.161 & 0.014 \\
\hline & $\mathrm{C}^{5} \mathrm{C}-\mathrm{H}_{\mathrm{Me}}{ }^{[a]}$ & 1.091 & 1.899 & -23.970 & -1.043 & 0.160 & 0.014 \\
\hline & $\mathrm{C}^{6} \mathrm{C}-\mathrm{H}_{\mathrm{Me}}{ }^{[a]}$ & 1.090 & 1.901 & -24.011 & -1.046 & 0.162 & 0.014 \\
\hline & $\mathrm{N}^{4} \mathrm{C}-\mathrm{H}_{\mathrm{Me}}{ }^{[a]}$ & 1.086 & 1.959 & -25.665 & -1.058 & 0.141 & 0.033 \\
\hline \multirow[t]{5}{*}{$\overline{5 b^{+}}$} & $\mathrm{C}^{3}-\mathrm{H}$ & 1.081 & 2.006 & -27.297 & -1.075 & 0.122 & 0.031 \\
\hline & $\mathrm{C}^{5} \mathrm{C}-\mathrm{H}_{\mathrm{CH} 2}{ }^{[b]}$ & 1.092 & 1.895 & -23.875 & -1.040 & 0.158 & 0.012 \\
\hline & $\mathrm{C}^{5} \mathrm{CH}_{2} \mathrm{C}-\mathrm{H}_{\mathrm{Me}}{ }^{[a]}$ & 1.092 & $\overline{1.899}$ & $\overline{-23.888}$ & $\overline{-1.042}$ & 0.162 & 0.014 \\
\hline & $\mathrm{C}^{6}-\mathrm{H}$ & 1.083 & 1.996 & -27.018 & -1.070 & 0.122 & 0.028 \\
\hline & $\mathrm{N}^{4} \mathrm{C}-\mathrm{H}_{\mathrm{Me}}{ }^{[a]}$ & 1.088 & 1.952 & -25.526 & -1.054 & 0.138 & 0.033 \\
\hline
\end{tabular}

${ }^{[a]}$ Average values for the three Me hydrogen atoms. ${ }^{[b]}$ Average values for the two $\mathrm{CH}_{2}$ hydrogen atoms. ${ }^{[c]}$ Bond path length. ${ }^{[d]}$ Electron density at the $b c p$ (smallest value of each complex underlined). ${ }^{[e]}$ Laplacian of the electron density at the $b c p$ (smallest absolute value of each complex underlined). ${ }^{[f]}$ Total energy density ratio at the $b c p$ (smallest absolute value of each complex underlined). ${ }^{[g]}$ Kinetic energy density ratio at the $b c p .{ }^{[h]}$ Ellipticity at the $b c p$.
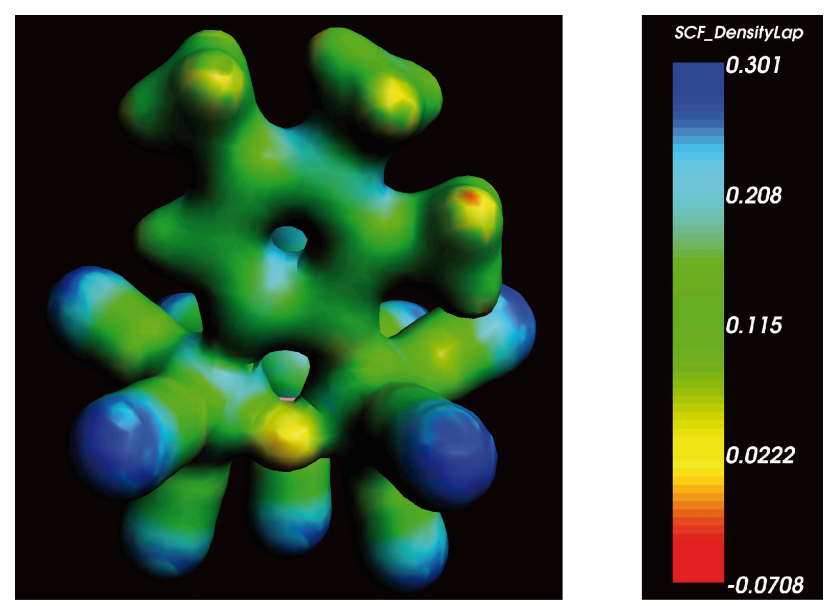

Figure 4. Three-dimensional representation of the molecular Laplacian of the electron density of $\mathbf{3 \mathbf { b } ^ { + }}$ mapped on an electron density isosurface at $0.34 \mathrm{e} \AA^{-3}$.

$\mathrm{C}^{3}-\mathrm{Me} \mathrm{H}$ atoms of $3 \mathbf{b}^{+}(0.248)$ with respect to those of $\mathbf{4} \mathbf{b}^{+}$ $(0.245)$. It should be noted that, for compounds having various $\mathrm{C}$ alkyl groups, the deprotonation experimentally occurs (Scheme 3) on the $\mathrm{C}$-alkyl group whose $\mathrm{H}$ atoms bear the highest atomic charge (Figure 3).

As the differences between the computed NBO charges of the ligand $\mathrm{H}$ atoms of each cluster are small, we sought for additional data that could also help rationalize the regioselectivity of the deprotonation reactions. Considering that there could be a relationship between the acidity of a $\mathrm{C}-\mathrm{H}$ bond and the topological parameters of its electron density, we used the Quantum Theory of Atoms in Molecules (QTAIM) ${ }^{[15]}$ which has been identified as a very powerful tool to analyze chemical bonding, ${ }^{[16]}$ to obtain the most relevant topological parameters of the electron density associated to each $\mathrm{C}-\mathrm{H}$ bond of compounds $\mathbf{1} \mathbf{b}^{+}-\mathbf{5} \mathbf{b}^{+}$. Table 1 shows that, although the values obtained for a particular topological parameter are not very different for the various $\mathrm{C}-\mathrm{H}$ bonds of each cluster, the $\mathrm{C}-\mathrm{H}$ bond that is experimentally deprotonated in each case coincides with that having the smallest bond critical point $(b c p)$ electron density $\left(\rho_{\mathrm{b}}\right)$, the smallest absolute value for the Laplacian of the electron density at the $b c p\left(\nabla^{2} \rho_{\mathrm{b}}\right)$, and the the smallest absolute value for the total energy density ratio at the $b c p\left(H_{\mathrm{b}} / \rho_{\mathrm{b}}\right)$, with the remaining topological parameters showing less significant trends. As these parameters can be related to the bond strength, ${ }^{[15,16]}$ it can be stated that the deprotonation of clusters $\mathbf{1} \mathbf{b}^{+}-\mathbf{5} \mathbf{b}^{+}$occurs on the weakest $\mathrm{C}-\mathrm{H}$ bond of each cluster. A three dimensional representation of the molecular Laplacian of the electron density visually helps identify the $\mathrm{C}-\mathrm{H}$ bond that is most predisposed to undergo deprotonation (Figure 4).

As occurs with the NBO charges, the differences between the QTAIM data of the ligand $\mathrm{C}-\mathrm{H}$ bonds of each cluster are not large enough to solely justify the presence of only one product in the deprotonation reactions. Therefore, these reactions should also be influenced by factors that have not been included in the computations such as cation-anion interactions, solvent effects, etc.

Themolysis of compound 3c. Experimental and theoretical studies: With the aim to address the higher stability of compound 3c (it is stable at room temperature) in comparison with those of the related decacarbonyl species that are the primary products of the deprotonation of compounds $1 \mathbf{a}, \mathbf{2 a}, \mathbf{4 a}$ and $\mathbf{5 a}$ (they evolve to the corresponding nonacarbonyl derivatives at subambient 
temperatures; Schemes 3 and 4), we studied the thermolysis of $\mathbf{3 c}$ both experimentally and by theoretical calculations.

The heating of compound $3 \mathrm{c}$ in THF at $50{ }^{\circ} \mathrm{C}$ slowly (it took $c a .8 \mathrm{~h}$ to observe the complete disappearance of the starting cluster) led to a $c a$. 1:5 mixture of the nonacarbonyl derivatives 3d and 3e (Scheme 5). The reaction was performed in a Schlenk tube, initially under a nitrogen atmosphere, closed by a silicone bubbler. The final ratio of the reaction products and the reaction time depended on the number of times the system was opened (with nitrogen purge of the gas phase) to monitor the reaction (by IR and/or TLC). A reaction monitored by ${ }^{1} \mathrm{H}$ NMR revealed that 3d was the first compound formed, but, while the amount of $\mathbf{3 e}$ increased with the reaction time, that of $\mathbf{3 d}$ remained nearly constant until the end of the reaction. Compound $\mathbf{3 d}$ could not be isolated free of 3e. The treatment of this mixture with $\mathrm{CO}$ (gas bubbled) reformed compound $\mathbf{3 c}$.

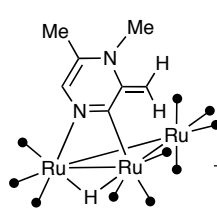

(3c)

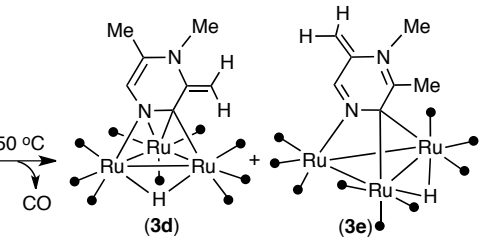

Scheme 5. Thermolysis of compound $\mathbf{3 c}$.
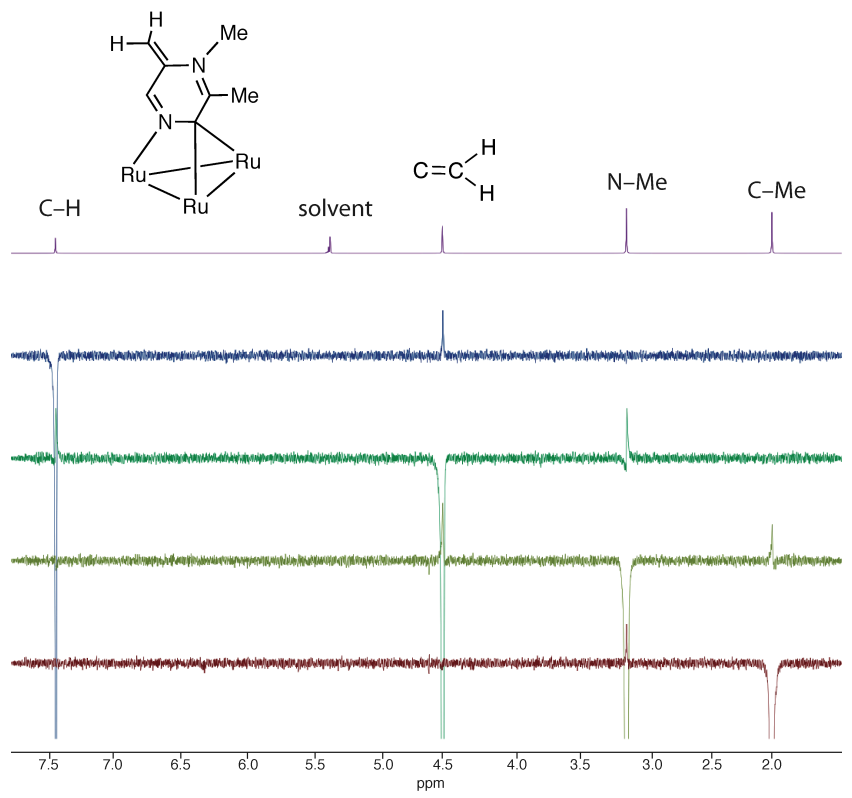

Figure 5. ${ }^{1} \mathrm{H}$ NMR $\left(\mathrm{CD}_{2} \mathrm{Cl}_{2}, 293 \mathrm{~K}, 400 \mathrm{MHz}\right)$ in the positive ppm region of compound 3e (top) and 1D NOE-difference spectra after saturation at the frequencies of the inverted signals.

The ${ }^{1} \mathrm{H}$ NMR shift of the hydride of compound 3d $(-17.14$ ppm) is comparable to that of $\left[\mathrm{Ru}_{3}(\mu-\mathrm{H})\left(\mu-\kappa^{2} N, C\right.\right.$-pyMe $\left.)(\mathrm{CO})_{9}\right]$ $(\text { pyMe }=\mathrm{N} \text {-methylpyrid-2-ylidene })^{[4]}$ and other similarly bridged nonacarbonyl triruthenium clusters. ${ }^{[7]}$ In addition, the ${ }^{1} \mathrm{H}$ NMR shift of the hydride of compound 3e $(-13.90 \mathrm{ppm})$ and its IR $v_{\mathrm{CO}}$ absorption pattern are comparable to those of $\mathbf{1 c}, \mathbf{2 c}, \mathbf{4 c}, \mathbf{5 c}$. These data confirm that the ligand arrangements around the $\mathrm{Ru}_{3}$ cores of compounds $\mathbf{3 d}$ and $\mathbf{3 e}$ are those shown in Scheme 5. The location of the methylidene group in each cluster was established by NOE ${ }^{1} \mathrm{H}$ NMR. Figure 5 unequivocally demonstrates that the $\mathrm{C}=\mathrm{CH}_{2}$ group of $\mathbf{3 e}$, which is observed as a singlet at $4.50 \mathrm{ppm}$, is close to both the $\mathrm{N}-\mathrm{Me}$ group and the $\mathrm{C}^{6}-\mathrm{H}$ proton, while the latter is far away from the $\mathrm{C}-\mathrm{Me}$ group.

Therefore, while the reaction that gives $\mathbf{3 d}$ from $\mathbf{3 c}$ is a simple decarbonylation process, the reaction that leads to $\mathbf{3 e}$ also implies a surprising rearrangement that "apparently" involves a hydrogen shift from the $\mathrm{C}^{5}$-methyl group to the $\mathrm{C}^{3}$-methylene group.

To explain these results, the mechanisms of the reactions $\mathbf{3 c}$ $\rightarrow \mathbf{3 d}+\mathrm{CO}$ and $\mathbf{3 c} \rightarrow \mathbf{3 e}+\mathrm{CO}$ were theoretically investigated by exploring their associated potential energy surfaces in the gas phase. These calculations were carried out by DFT methods at the B3LYP/LanL2DZ/6-31G(d,p) level of theory.

Figure 6 shows that the reaction $\mathbf{3 c} \rightarrow \mathbf{3 d}+\mathrm{CO}$ is an elemental process that implies the displacement of an axial $\mathrm{CO}$ ligand from the $\mathrm{Ru}(\mathrm{CO})_{4}$ fragment of $3 \mathbf{c}$ by the metalated $\mathrm{C}=\mathrm{N}$ double bond of the bridging ligand. The calculated energy barrier of this process, $23.9 \mathrm{kcal} \mathrm{mol}^{-1}$, is not low enough to be easily accessible at room temperature but is easily reachable at $50{ }^{\circ} \mathrm{C}$. As the energy of the reaction products $(\mathbf{3 d}+\mathrm{CO})$ is higher than that of $\mathbf{3 c}$, the amount of $\mathbf{3 c}$ in the equilibrium should be larger than that of $\mathbf{3 d}$ if $\mathrm{CO}$ is not evacuated from the system.

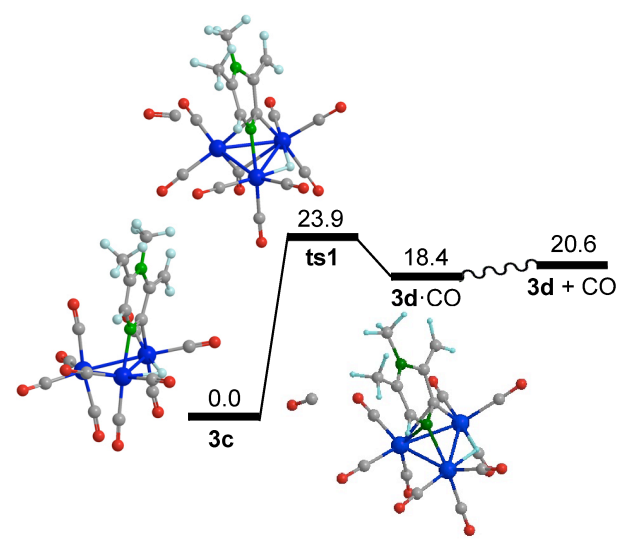

Figure 6. DFT-calculated mechanism for the transformation of $\mathbf{3 c}$ into $\mathbf{3 d}+\mathrm{CO}$. The given energies $\left(\Delta \mathrm{E}, \mathrm{kcal} \mathrm{mol}^{-1}\right)$ are relative to that of $\mathbf{3 c}$.

Figures 7 and 8 display a calculated mechanism that accounts for the transformation of $\mathbf{3} \mathbf{c}$ into $\mathbf{3 e}+\mathrm{CO}$. The first step (Figure 7) is a reductive elimination process, which engages the hydride and the metalated carbon atom of the bridging ligand and converts complex 3c into a coordinatively unsaturated intermediate having a terminally bound pyrazinum-type ligand (i1). A $180^{\circ}$ rotation of this ligand about the $\mathrm{Ru}-\mathrm{N}$ bond places the original $\mathrm{C}^{6}-\mathrm{H}$ hydrogen atom in close proximity to the unsaturated $\mathrm{Ru}$ atom (i2). A subsequent orthometalation (oxidative addition) of this bond leads to intermediate i3, whose ligand arrangement is analogous to $3 \mathbf{c}$ but has the methylidene group in position 5 of the ligand ring. This implies that $\mathbf{3 c}$ and $\mathbf{i} \mathbf{3}$ also have a different distribution of double and single bonds in their corresponding ligand ring, e.g., the $\mathrm{N}^{1}$ and $\mathrm{C}^{2}$ atoms are connected through a double bond in $\mathbf{3 c}$ $\left(\mathrm{N}^{1}-\mathrm{C}^{2} 1.35 \AA\right)$ but through a single bond in $\mathbf{i} 3\left(\mathrm{~N}^{1}-\mathrm{C}^{2} 1.40 \AA\right)$, and this fact accounts for their different energies (i3 is $6.5 \mathrm{kcal}$ $\mathrm{mol}^{-1}$ less stable than $\mathbf{3 c}$ ). The barrier to the isomerization of $\mathbf{3 c}$ into $3 \mathrm{e}\left(37.1 \mathrm{kcal} \mathrm{mol}^{-1}\right)$ is also accessible at $50{ }^{\circ} \mathrm{C}$ but is 13.2 kcal mol ${ }^{-1}$ higher than that of the transformation of $\mathbf{3 c}$ into $\mathbf{3 d}+$ $\mathrm{CO}$ (Figure 8 ). This explains the experimental fact that compound $\mathbf{3 d}$ is the first product observed during the thermolysis of $\mathbf{3 c}$. 
The approach of the $\mathrm{C}^{2}$ carbon atom of intermediate $\mathbf{3}$ toward the $\mathrm{Ru}(\mathrm{CO})_{4}$ fragment provokes a terminal-to-bridging rearrangement of one of its axial CO ligands (ts5, Figure 8) that induces the release of the CO ligand that is trans to the bridging $\mathrm{CO}$ and cis to the hydride in ts5. In the resulting intermediate, i4, the heterocyclic ligand caps the $\mathrm{Ru}_{3}$ triangle. Although the energy of $\mathbf{i} \mathbf{4}+\mathrm{CO}$ is higher than that of $\mathbf{i} 3$, the energy barrier of this step is small $\left(18.8 \mathrm{kcal} \mathrm{mol}^{-1}\right)$ and the transformation of $\mathbf{i 4}$ into the final product $3 \mathbf{e}$ (in two steps that imply a $\mathrm{CO}$ rearrangement and a $c a .60^{\circ}$ rotation of the capping ligand over the $\mathrm{Ru}_{3}$ triangle) is kinetically (low activation barrier) and thermodynamically favored (3e is $4.4 \mathrm{kcal} \mathrm{mol}^{-1}$ more stable than i4). In addition, the evacuation of $\mathrm{CO}$ from the reaction system stimulates the transformation of $\mathbf{i} \mathbf{3}$ into $\mathbf{3 e}$. no $\mathrm{CO}$ in the atmosphere, $\mathbf{3 d}$ is formed more quickly than $\mathbf{3 e}$ (kinetic control). The amount of $\mathbf{3 d}$ does not increase during the reaction because part of the $\mathrm{CO}$ released in the formation of $\mathbf{3 e}$ from 3c (another part is progressively evacuated) reacts easily with 3d to reform 3c. On the other hand, 3d does not disappear at the end of the reaction because the system does not have enough CO available.

We also found a mechanism for a direct transformation of $\mathbf{3 d}$ into 3e (not implicating 3c), but various steps of such a reaction pathway have much higher activation barriers than those involved in the mechanisms shown in Figures 6-8. Consequently, we do not believe that $\mathbf{3 d}$ be an intermediate in the transformation of $\mathbf{3 c}$ into $3 \mathbf{e}+\mathrm{CO}$.

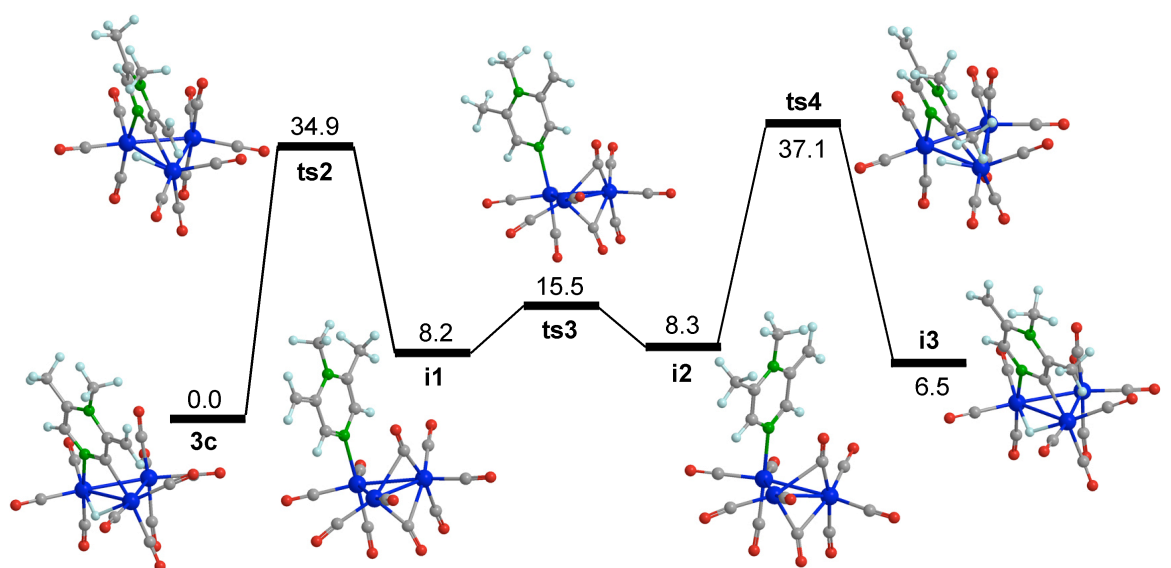

Figure 7. DFT-calculated mechanism for the transformation of $\mathbf{3} \mathbf{c}$ into $\mathbf{3 e}+\mathrm{CO}$. Part 1: From $3 \mathbf{c}$ to i3. The given energies $\left(\Delta \mathrm{E}, \mathrm{kcal} \mathrm{mol}^{-1}\right)$ are relative to that of $\mathbf{3 c}$.
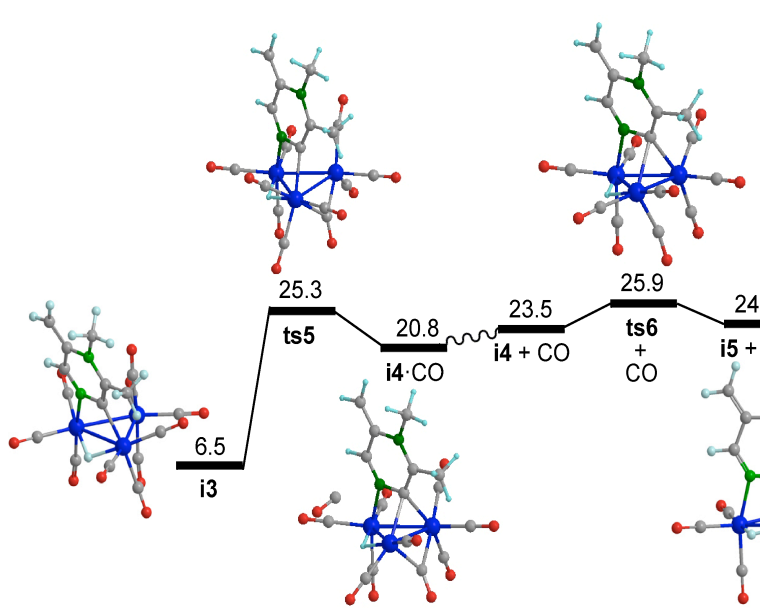

Figure 8. DFT-calculated mechanism for the transformation of $\mathbf{3 c}$ into $3 \mathbf{e}+\mathrm{CO}$. Part 2: From i3 to $\mathbf{3 e}+\mathrm{CO}$. The given energies $\left(\Delta \mathrm{E}, \mathrm{kcal} \mathrm{mol}^{-1}\right)$ are relative to that of $\mathbf{3 c}$.

Experimentally, the thermolysis reaction was performed in a Schlenk tube, initially under a nitrogen atmosphere, closed by a silicone bubbler. Therefore, part of the CO released from the thermolysis was evacuated through the bubbler, but another part was maintained inside the system. The facts that a) the direct $\mathrm{CO}$ elimination from $\mathbf{i} 3$ (once formed; Figure 8) is easier than that from $\mathbf{3 c}$ (Figure 6), b) the transformation of $\mathbf{i} 4$ into $3 \mathbf{e}$ is very easy and thermodynamically favored, c) $\mathrm{CO}$ is progressively removed from he reaction system, and d) $\mathbf{3 e}$ is thermodynamically more stable (by $1.5 \mathrm{kcal} \mathrm{mol}^{-1}$ ) than 3d, explain that, at the end of the experiment, the amount of $\mathbf{3 e}$ is greater than that of $\mathbf{3 d}$ (thermodynamic control) although at the beginning, when there is
The mechanism shown in Figure 8 also explains why no decacarbonyl $\mathrm{C}^{5}$ alkylidene intermediates were observed when the deprotonations of $\mathbf{1 b}, \mathbf{2 b}, \mathbf{4 b}$ and $\mathbf{5 b}$, which undergo deprotonation at their $\mathrm{C}^{5}$-alkyl group, were carried out at room temperature (Scheme 3), but they were detected in reactions performed at lower temperature before ending in the final nonacarbonyl products $1 c, 2 c, 4 c$ and $5 c$, respectively, when the temperature was raised (Scheme 4). As these decacarbonyl $\mathrm{C}^{5}$-alkylidene intermediates should be structurally similar to intermediate $\mathbf{i} 3$ (they all have the alkylidene group in position 5 of the ligand ring and have the same distribution of single and double bonds within the ring), they should easily release CO (irreversibly in an unsealed system) to give the corresponding nonacarbonyl derivatives.

\section{Conclusions}

This manuscript demonstrates that the Calkyl groups of cationic triruthenium cluster complexes containing ligands derived from $\mathrm{C}$-alkyl $\mathrm{N}$-methylpyridinium can be deprotonated to give unprecedented C-alkylidene derivatives.

Theoretical calculations support the proposal that, when the starting complexes contain various C-alkyl groups, the selectivity of these deprotonation reactions is primarily determined by the atomic charge of the alkyl $\mathrm{H}$ atoms, the higher the charge the easier the deprotonation. Three additional electronic properties of the $\mathrm{C}$ alkyl $\mathrm{C}-\mathrm{H}$ bonds have also been found to be related to the experimental regioselectivity, since, for each starting complex, the deprotonated $\mathrm{C}-\mathrm{H}$ bond is that having the smallest electron density at the bond critical point, the greatest Laplacian of the electron density at the bond critical point, and the greatest total energy density ratio at the bond critical point. This type of calculations may be useful for researches interested in the reactivity of $\mathrm{C}-\mathrm{H}$ bonds. 
It has been established that the distribution of single and double bonds within the heterocyclic ligands of the deprotonated products (C-alkylidene derivatives) determines affects the stability of the decacarbonyl intermediates (kinetic products) and also the structures (the coordination of the ligand to the metal atoms) of the final nonacarbonyl complexes (thermodynamic products). Thus, while the edge-bridged decacarbonyl derivative 3c, which has a $\mathrm{C}^{3}$-methylidene group, is isolable at room temperature, the related decacarbonyl $\mathrm{C}^{5}$-alkylidene derivatives are unstable at room temperature, evolving toward the corresponding face-capped nonacarbonyl products $1 \mathbf{c}, \mathbf{2 c}, \mathbf{4 c}$ and 5c. Two face-capped nonacarbonyl products, $\mathbf{3 d}$ and $\mathbf{3 e}$, have been isolated after heating compound $3 \mathbf{c}$ in THF at $50{ }^{\circ} \mathrm{C}$. While 3d maintains the original $\mathrm{C}$-methylidene group in position 3 of its heterocyclic ligand, the methylidene group of $\mathbf{3 e}$ is in position 5 .

The mechanisms by which the edge-bridged C-alkylidene decacarbonyl (kinetic) products are transformed into the corresponding nonacarbonyl derivatives (thermodynamic products) have been investigated by DFT methods. These studies have rationalized not only the structures of the final products but have also shed light on the kinetic and thermodynamic stability of the reaction intermediates, explaining the reaction conditions experimentally required by each transformation.

In addition, this work opens up the possibility of extending the deprotonation C-alkyl-N-heterocyclic ligands to mononuclear complexes and also gives the initial step toward the functionalization of such ligands via C-alkylidene intermediates, processes that have not been hitherto investigated.

\section{Experimental Section}

General: Solvents were dried over $\mathrm{Na}\left[\mathrm{Ph}_{2} \mathrm{CO}\right]$ (THF, diethyl ether, hydrocarbons) or $\mathrm{CaH}_{2}$ (dichloromethane) and were distilled under nitrogen prior to use. The reactions were carried out under nitrogen, using Schlenk-vacuum line techniques, and were routinely monitored by solution IR spectroscopy and by spot TLC on silica gel. All reagents were purchased from commercial sources. All reaction products were vacuum-dried for several hours prior to being weighted and analyzed. IR: PerkinElmer FT Paragon 1000X. NMR: Bruker AV-400, AV-300, NAV-400, and DPX300 , room temperature (r.t.), residual solvent as internal standard. Microanalyses: Perkin-Elmer 2400B. MS: VG Autospec double-focusing mass spectrometer operating in the $\mathrm{FAB}+$ mode; ions were produced with a standard $\mathrm{Cs}^{+}$gun at about $30 \mathrm{kV}$; 3-nitrobenzyl alcohol was used as matrix; data given correspond to the most abundant molecular ion isotopomer. The experimental details of the syntheses of compounds 1a-5a and 1b-5b (Scheme 2) and their spectroscopic and other analytical data are given in the Supporting Information.

$\left[\mathrm{Ru}_{3}(\mu-\mathrm{H})\left(\mu_{3}-\mathrm{K}^{2} N^{1}, C^{2}-4-\mathrm{Me}-5-\mathrm{CH}_{2}-\mathrm{C}_{4} \mathrm{H}_{2} \mathrm{~N}_{2}\right)(\mathrm{CO})_{9}\right](\mathbf{c})$ : A toluene solution of $\mathrm{K}\left[\mathrm{N}\left(\mathrm{SiMe}_{3}\right)_{2}\right](355 \mu \mathrm{L}, 0.5 \mathrm{M}, 0.178 \mathrm{mmol})$ was dropwise added to a suspension of compound $\mathbf{1 b}(150 \mathrm{mg}, 0.178 \mathrm{mmol})$ in THF $(30 \mathrm{~mL})$ at $-80{ }^{\circ} \mathrm{C}$. The color changed from red to brown. The system was warmed up to room temperature and the solid was filtered off. An aliquot of the resulting solution was analyzed by ${ }^{1} \mathrm{H}$ NMR. The spectrum showed the presence of a mixture that comprised 1a (17\%), 1c (48\%), and smaller amounts of unidentified hydride-containing products. All attempts to obtain pure 1c by chromatographic methods (TLC and silica or alumina columns) were unsuccessful. ${ }^{1} \mathrm{H}$ NMR $\left(\mathrm{CD}_{2} \mathrm{Cl}_{2}\right.$, r.t., ppm): $\delta 7.52(\mathrm{~s}, 1 \mathrm{H}, \mathrm{CH}), 6.49(\mathrm{~s}, 1 \mathrm{H}, \mathrm{CH})$, $4.53\left(\mathrm{~d}, J=3.2 \mathrm{~Hz}, 1 \mathrm{H}, \mathrm{CH}_{2}\right), 4.45\left(\mathrm{~d}, J=3.2 \mathrm{~Hz}, 1 \mathrm{H}, \mathrm{CH}_{2}\right), 3.08\left(\mathrm{~s}, 3 \mathrm{H}, \mathrm{NCH}_{3}\right),-$ $14.56(\mathrm{~s}, 1 \mathrm{H}, \mu-H) .{ }^{13} \mathrm{C}\left\{{ }^{1} \mathrm{H}\right\}$ NMR $\left(\mathrm{CD}_{2} \mathrm{Cl}_{2}\right.$, r.t., ppm): $\delta$ 199.3, 195.9 (COs), 166.6 $(\mathrm{CH}), 151.7(\mathrm{CH}), 137.0(\mathrm{C}), 101.7(\mathrm{C}), 96.2\left(\mathrm{CH}_{2}\right), 40.8\left(\mathrm{NCH}_{3}\right)$.

$\left[\mathrm{Ru}_{3}(\mu-\mathrm{H})\left(\mu_{3}-\mathrm{K}^{2} N^{1}, C^{2}-4,6-\mathrm{Me}_{2}-5-\mathrm{CH}_{2}-\mathrm{C}_{4} \mathrm{HN}_{2}\right)(\mathrm{CO})_{9}\right]$ (2c): A toluene solution of $\mathrm{K}\left[\mathrm{N}\left(\mathrm{SiMe}_{3}\right)_{2}\right](175 \mu \mathrm{L}, 0.5 \mathrm{M}, 0.088 \mathrm{mmol})$ was dropwise added to a suspension of compound $2 \mathbf{b}(75 \mathrm{mg}, 0.088 \mathrm{mmol})$ in THF $(30 \mathrm{~mL})$ at $-80{ }^{\circ} \mathrm{C}$. The color changed from orange to brown. The system was warmed up to room temperature and the solid was filtered off. An aliquot of the resulting solution was analyzed by ${ }^{1} \mathrm{H}$ NMR. The spectrum showed the presence of a mixture of $2 \mathbf{a}(5 \%)$ and $\mathbf{2 c}(95 \%)$. The solvent was removed under reduced pressure, the residue was extracted into dichloromethane $(1.5 \mathrm{~mL})$, and this solution was placed onto an alumina column $(2 \times 10 \mathrm{~cm}$, activity
IV) packed in hexane. Hexane eluted a trace amount of $\left[\mathrm{Ru}_{3}(\mathrm{CO})_{12}\right]$. Hexanedichloromethane (4:1) eluted compound $\mathbf{2 c}$, which was isolated as an orange solid (50 mg, 84\%). Analysis (\%) found (calcd. for $\mathrm{C}_{16} \mathrm{H}_{10} \mathrm{~N}_{2} \mathrm{O}_{9} \mathrm{Ru}_{3}$ ): $\mathrm{C} 28.41$ (28.37); $\mathrm{H}$ 1.58 (1.49); N 4.05 (4.14). +FAB MS (MW, amu): 679 (677.47). IR $\left(\mathrm{CH}_{2} \mathrm{Cl}_{2}, \mathrm{~cm}^{-1}\right)$ : v(CO) 2069 (w), 2038 (vs), 2018 (m), 1989 (m, br), 1973 (w, sh). ${ }^{1} \mathrm{H}$ NMR $\left(\mathrm{CD}_{2} \mathrm{Cl}_{2}\right.$, r.t., ppm): $\delta 6.54(\mathrm{~s}, 1 \mathrm{H}, \mathrm{CH}), 4.77\left(\mathrm{~d}, J=4.0 \mathrm{~Hz}, 1 \mathrm{H}, \mathrm{CH}_{2}\right), 4.53(\mathrm{~d}, J=4.0 \mathrm{~Hz}, 1$ $\left.\mathrm{H}, \mathrm{CH}_{2}\right), 3.15\left(\mathrm{~s}, 3 \mathrm{H}, \mathrm{NCH} H_{3}\right), 2.19\left(\mathrm{~s}, 3 \mathrm{H}, \mathrm{CH}_{3}\right),-14.70(\mathrm{~s}, 1 \mathrm{H}, \mu-H) .{ }^{13} \mathrm{C}\left\{{ }^{1} \mathrm{H}\right\}$ NMR $\left(\mathrm{CD}_{2} \mathrm{Cl}_{2}\right.$, r.t., ppm): $\delta$ 205.4, $196.3(\mathrm{COs}), 166.7(\mathrm{CH}), 154.1(\mathrm{C}), 137.2(\mathrm{C})$, $101.5(\mathrm{C}), 95.2\left(\mathrm{CH}_{2}\right), 41.9\left(\mathrm{NCH}_{3}\right), 20.9\left(\mathrm{CH}_{3}\right)$.

$\left[\mathrm{Ru}_{3}(\mu-\mathrm{H})\left(\mu-\mathrm{K}^{2} N^{1}, C^{2}-3-\mathrm{CH}_{2}-4,5-\mathrm{Me}_{2}-\mathrm{C}_{4} \mathrm{HN}_{2}\right)(\mathrm{CO})_{10}\right]$ (3c): A toluene solution of $\mathrm{K}\left[\mathrm{N}\left(\mathrm{SiMe}_{3}\right)_{2}\right](175 \mu \mathrm{L}, 0.5 \mathrm{M}, 0.082 \mathrm{mmol})$ was dropwise added to a suspension of compound $3 \mathbf{b}(70 \mathrm{mg}, 0.082 \mathrm{mmol})$ in THF $(30 \mathrm{~mL})$ at $-80{ }^{\circ} \mathrm{C}$. The color changed from orange to brown. The system was warmed up to room temperature and the solid was filtered off. An aliquot of the resulting solution was analyzed by ${ }^{1} \mathrm{H}$ NMR. The spectrum showed the only presence of complex $3 \mathbf{c}$. The solvent was removed under reduced pressure and the resulting oily solid was washed with hexane $(5 \mathrm{~mL})$ to give compound $3 \mathbf{c}$ as an orange solid (40 mg, 69\%). Analysis (\%) found (calcd. for $\mathrm{C}_{17} \mathrm{H}_{10} \mathrm{~N}_{2} \mathrm{O}_{10} \mathrm{Ru}_{3}$ ): C 29.0 (28.94); $\mathrm{H} 1.48$ (1.43); N 3.91 (3.97). +FAB MS (MW, amu): 707 (705.48). IR $\left(\mathrm{CH}_{2} \mathrm{Cl}_{2}, \mathrm{~cm}^{-1}\right)$ : v(CO) 2098 (w), 2059 (s), 2046 (vs), 2012 (m, br), 1993 (m, sh), 1976 (w, sh). ${ }^{1} \mathrm{H} \mathrm{NMR}\left(\mathrm{CD}_{2} \mathrm{Cl}_{2}\right.$, r.t., ppm): $\delta 5.78$ (s, $\left.1 \mathrm{H}, \mathrm{CH}\right)$, $4.38\left(\mathrm{~d}, J=2.4 \mathrm{~Hz}, 1 \mathrm{H}, \mathrm{CH}_{2}\right), 4.11\left(\mathrm{~d}, J=2.4 \mathrm{~Hz}, 1 \mathrm{H}, \mathrm{CH}_{2}\right), 2.90\left(\mathrm{~s}, 3 \mathrm{H}, \mathrm{NCH}_{3}\right)$, $1.96\left(\mathrm{~s}, 3 \mathrm{H}, \mathrm{CH} \mathrm{H}_{3}\right),-14.66(\mathrm{~s}, 1 \mathrm{H}, \mu-H) .{ }^{13} \mathrm{C}\left\{{ }^{1} \mathrm{H}\right\} \operatorname{NMR}\left(\mathrm{CD}_{2} \mathrm{Cl}_{2}\right.$, r.t., ppm): $\delta 208.3$, 205.6, 201.8, 201.4, 196.7, 195.7, 192.2, 191.4, 191.0, 186.8 (10 COs), 185.8 (C), $148.3(C), 134.8(C), 120.0(C H), 89.1\left(\mathrm{CH}_{2}\right), 34.2\left(\mathrm{NCH}_{3}\right), 16.8\left(\mathrm{CH}_{3}\right)$.

$\left[\mathrm{Ru}_{3}(\mu-\mathrm{H})\left(\mu_{3}-\kappa^{2} N^{1}, C^{2}-3,4,6-\mathrm{Me}_{3}-5-\mathrm{CH}_{2}-\mathrm{C}_{4} \mathrm{~N}_{2}\right)(\mathrm{CO})_{9}\right]$ (4c): A toluene solution of $\mathrm{K}\left[\mathrm{N}\left(\mathrm{SiMe}_{3}\right)_{2}\right](195 \mu \mathrm{L}, 0.5 \mathrm{M}, 0.098 \mathrm{mmol})$ was dropwise added to a suspension of compound $4 \mathbf{b}(85 \mathrm{mg}, 0.098 \mathrm{mmol})$ in THF $(30 \mathrm{~mL})$ at $-80{ }^{\circ} \mathrm{C}$. The color changed from red to brown. The system was warmed up to room temperature and the solid was filtered off. An aliquot of the resulting solution was analyzed by ${ }^{1} \mathrm{H}$ NMR. The spectrum showed the presence of a mixture that comprised $4 \mathbf{a}(20 \%), 4 \mathbf{c}(70 \%)$, and smaller amounts of unidentified hydride-containing products. The solvent was removed under reduced pressure, the residue was extracted into dichloromethane (2 $\mathrm{mL})$, and this solution was placed onto an alumina column $(2 \times 10 \mathrm{~cm}$, activity IV) packed in hexane. Hexane eluted a trace amount of $\left[\mathrm{Ru}_{3}(\mathrm{CO})_{12}\right]$. Hexanedichloromethane (4:1) eluted compound $\mathbf{4 c}$, which was isolated as an orange solid (35 mg, 52\%). Analysis (\%) found (calcd. for $\mathrm{C}_{17} \mathrm{H}_{12} \mathrm{~N}_{2} \mathrm{O}_{9} \mathrm{Ru}_{3}$ ): C 29.60 (29.53); H 1.80 (1.75); N 3.99 (4.05). +FAB MS (MW, amu): 693 (691.50). IR $\left(\mathrm{CH}_{2} \mathrm{Cl}_{2}, \mathrm{~cm}^{-1}\right)$ : $v(\mathrm{CO}) 2069$ (w), 2038 (vs), 2018 (m), 1989 (m, br), 1973 (w, sh). ${ }^{1} \mathrm{H}$ NMR $\left(\mathrm{CD}_{2} \mathrm{Cl}_{2}\right.$, r.t., ppm): $\delta 4.76\left(\mathrm{~d}, J=3.7 \mathrm{~Hz}, 1 \mathrm{H}, \mathrm{CH}_{2}\right), 4.61\left(\mathrm{~d}, J=3.7 \mathrm{~Hz}, 1 \mathrm{H}, \mathrm{CH}_{2}\right), 3.17$ (s, 3 $\left.\mathrm{H}, \mathrm{NCH}_{3}\right), 2.43\left(\mathrm{~s}, 3 \mathrm{H}, \mathrm{CH}_{3}\right), 2.04\left(\mathrm{~s}, 3 \mathrm{H}, \mathrm{CH}_{3}\right),-14.04(\mathrm{~s}, 1 \mathrm{H}, \mu-H) .{ }^{13} \mathrm{C}\left\{{ }^{1} \mathrm{H}\right\}$ NMR $\left(\mathrm{CD}_{2} \mathrm{Cl}_{2}\right.$, r.t., ppm): $\delta$ 206.4, $196.0(\mathrm{COs}), 180.7(C), 152.0(C), 137.3(C)$, $106.8(C), 95.2\left(\mathrm{CH}_{2}\right), 37.7\left(\mathrm{NCH}_{3}\right), 24.6\left(\mathrm{CH}_{3}\right), 21.4\left(\mathrm{CH}_{3}\right)$.

$\left[\mathrm{Ru}_{3}(\mu-\mathrm{H})\left(\mu_{3}-\mathrm{K}^{2} N^{1}, C^{2}-4-\mathrm{Me}-5-\mathrm{CHMe}-\mathrm{C}_{4} \mathrm{H}_{2} \mathrm{~N}_{2}\right)(\mathrm{CO})_{9}\right](\mathbf{5 c})$ : A toluene solution of $\mathrm{K}\left[\mathrm{N}\left(\mathrm{SiMe}_{3}\right)_{2}\right](230 \mu \mathrm{L}, 0.5 \mathrm{M}, 0.117 \mathrm{mmol})$ was dropwise added to a suspension of compound $\mathbf{5 b}(100 \mathrm{mg}, 0.117 \mathrm{mmol})$ in THF $(30 \mathrm{~mL})$ at $-80{ }^{\circ} \mathrm{C}$. The color changed from red to dark brown. The system was warmed up to room temperature and the solid was filtered off. An aliquot of the resulting solution was analyzed by ${ }^{1} \mathrm{H}$ NMR. The spectrum showed the presence of a mixture that comprised 5a $(20 \%), \mathbf{5 c}(30 \%)$, and other unidentified products. The solvent was removed under reduced pressure, the residue was extracted into dichloromethane $(1.5 \mathrm{~mL})$, and this solution was placed onto a silica gel column $(2 \times 10 \mathrm{~cm})$ packed in hexane. Hexane eluted a red band containing a mixture of unidentified compounds. Hexane-dichloromethane (3:1) eluted an orange band that also contained a mixture of unidentified compounds. Further elution with the same solvent mixture eluted a yellow-orange band that contained compounds $\mathbf{5 a}$ and $\mathbf{5 c}$. This solution was evaporated to dryness and the solid residue was washed with hexane $(2 \times 4 \mathrm{~mL})$ to give compound $\mathbf{5 c}$ as an orange solid (20 mg, 25\%). Analysis (\%) found (calcd. for $\mathrm{C}_{16} \mathrm{H}_{10} \mathrm{~N}_{2} \mathrm{O}_{9} \mathrm{Ru}_{3}$ ): C 28.43 (28.37); H 1.55 (1.49); N 4.07 (4.14). +FAB MS (MW, amu): 679 (677.47). IR $\left(\mathrm{CH}_{2} \mathrm{Cl}_{2}, \mathrm{~cm}^{-1}\right)$ : v(CO) 2070 (w), 2039 (vs), 2020 (s), 1990 (m, br), 1975 (w, sh), 1948 (vw, sh). ${ }^{1} \mathrm{H}$ NMR $\left(\mathrm{CD}_{2} \mathrm{Cl}_{2}\right.$, r.t., ppm): $\delta 7.70$ (s, $\left.1 \mathrm{H}, \mathrm{CH}\right), 6.43$ (s, $\left.1 \mathrm{H}, \mathrm{CH}\right)$, $4.95(\mathrm{q}, J=7.5 \mathrm{~Hz}, 1 \mathrm{H}, \mathrm{CH}), 3.02\left(\mathrm{~s}, 3 \mathrm{H}, \mathrm{NCH}_{3}\right), 1.83\left(\mathrm{~d}, J=7.5 \mathrm{~Hz}, 3 \mathrm{H}, \mathrm{CH}_{3}\right)$, $14.53(\mathrm{~s}, 1 \mathrm{H}, \mu-H) .{ }^{13} \mathrm{C}\left\{{ }^{1} \mathrm{H}\right\}$ NMR $\left(\mathrm{CD}_{2} \mathrm{Cl}_{2}\right.$, r.t., ppm): $\delta 205.0,196.4(\mathrm{COs}), 167.8$ $(\mathrm{CH}), 147.4(\mathrm{CH}), 130.8(\mathrm{C}), 108.1\left(\mathrm{CHCH}_{3}\right), 100.5(\mathrm{C}), 41.1\left(\mathrm{NCH}_{3}\right), 11.0$ $\left(\mathrm{CHCH}_{3}\right)$.

Thermolysis of 3c: A THF solution $(20 \mathrm{~mL})$ of compound $3 \mathbf{c}(20 \mathrm{mg}, 0.028 \mathrm{mmol})$ was stirred at $50{ }^{\circ} \mathrm{C}$ for $7.5 \mathrm{~h}$. The color changed from red to dark orange. An aliquot of the resulting solution was analyzed by ${ }^{1} \mathrm{H}$ NMR. The spectrum showed the presence of a mixture of $\mathbf{3 c}(15 \%), \mathbf{3 d}(15 \%)$, and $\mathbf{3 e}(70 \%)$. The solvent was removed under reduced pressure, the residue was extracted into dichloromethane (1.5 $\mathrm{mL})$, and this solution was placed onto a silica gel column $(2 \times 10 \mathrm{~cm})$ packed in hexane. Hexane eluted a red band containing a mixture of unidentified compounds. Hexane-dichloromethane (4:1) eluted two overlapping orange bands that contained, in order of elution, compounds $3 \mathbf{e}(11 \mathrm{mg}, 60 \%)$ and $\mathbf{3 d}$. The latter product could not be completely separated from some 3e. Data for $3 d$ : ${ }^{1} \mathrm{H} \mathrm{NMR}\left(\mathrm{CD}_{2} \mathrm{Cl}_{2}\right.$, r.t., ppm): $\delta$ $5.88(\mathrm{~s}, 1 \mathrm{H}, \mathrm{CH}), 4.46\left(\mathrm{~d}, J=2.1 \mathrm{~Hz}, 1 \mathrm{H}, \mathrm{CH}_{2}\right), 4.17\left(\mathrm{~d}, J=2.1 \mathrm{~Hz}, 1 \mathrm{H}, \mathrm{CH}_{2}\right), 2.87$ 
(s, $\left.3 \mathrm{H}, \mathrm{NCH}_{3}\right), 1.78\left(\mathrm{~s}, 3 \mathrm{H}, \mathrm{CH}_{3}\right),-17.14(\mathrm{~s}, 1 \mathrm{H}, \mu-H)$. Data for $3 \boldsymbol{e}$ : Analysis (\%) found (calcd. for $\mathrm{C}_{16} \mathrm{H}_{10} \mathrm{~N}_{2} \mathrm{O}_{9} \mathrm{Ru}_{3}$ ): C 28.43 (28.37); $\mathrm{H} 1.53$ (1.49); N 4.08 (4.18). +FAB MS (MW, amu): 679 (677.47). IR $\left(\mathrm{CH}_{2} \mathrm{Cl}_{2}, \mathrm{~cm}^{-1}\right)$ : v(CO) 2070 (w), 2039 (vs), $2020(\mathrm{~m}), 1990$ (m, sh), 1974 (w, sh). ${ }^{1} \mathrm{H}$ NMR $\left(\mathrm{CD}_{2} \mathrm{Cl}_{2}\right.$, r.t., ppm): $\delta 7.46$ (s, $1 \mathrm{H}$, $\mathrm{CH}), 4.50$ (s, $\left.2 \mathrm{H}, \mathrm{CH}_{2}\right), 3.10$ (s, $\left.3 \mathrm{H}, \mathrm{NCH}_{3}\right), 1.98\left(\mathrm{~s}, 3 \mathrm{H}, \mathrm{CH}_{3}\right),-13.90$ (s, $1 \mathrm{H}, \mu-$ H). ${ }^{13} \mathrm{C}\left\{{ }^{1} \mathrm{H}\right\}$ NMR $\left(\mathrm{CD}_{2} \mathrm{Cl}_{2}\right.$, r.t., ppm): $\delta 206.2,199.7,195.3$ (COs), 181.9 (C), 151.2 $(\mathrm{CH}), 137.8(\mathrm{C}), 106.7(\mathrm{C}), 96.2\left(\mathrm{CH}_{2}\right), 36.8\left(\mathrm{NCH}_{3}\right), 23.9\left(\mathrm{CH}_{3}\right)$.

X-ray diffraction analyses: Crystals of $\mathbf{2 c}$ and $\mathbf{4 c}$ were analyzed by X-ray diffraction methods. Selected crystal, measurement, and refinement data are given in the Supporting Information (Table S1). Diffraction data were collected on an Oxford Diffraction Xcalibur Nova diffractometer, using $\mathrm{Cu}-\mathrm{K} \alpha$ radiation. Empirical absorption corrections were applied using $\mathrm{XABS}^{[17]}$ (for 2c) and the SCALE3 ABSPACK algorithm as implemented in the program CrysAlisPro RED ${ }^{[18]}$ (for $\mathbf{4 c}$ ). Structures were solved by Patterson interpretation using the program DIRDIF. ${ }^{[19]}$ Isotropic and full matrix anisotropic least square refinements were carried out using SHELXL. ${ }^{[20]}$ All non-H atoms were refined anisotropically. The position of the hydride atom of $2 \mathbf{c}$ was calculated with XHYDEX. ${ }^{[21]}$ The hydride ligand and the hydrogen atoms bonded to $\mathrm{C} 8$ of $\mathbf{4 c}$ were located in a Fourier map. The remaining hydrogen atoms were set in calculated positions and refined riding on their parent atoms. The WINGX program system ${ }^{[2]}$ was used throughout the structure determinations. CCDC-832808 (2c) and CCDC-832809 (4c) contain the supplementary crystallographic data for this paper. These data can be obtained free of charge from the Cambridge Crystallographic Data Centre via www.ccdc.cam.ac.uk/data_request/cif.

Theoretical calculations: DFT computations (using the Gaussian09 program package $^{[23]}$ ) of NBO charges ${ }^{[24]}$ and QTAIM topological parameters (using the AIM2000 program ${ }^{[25]}$ ) were performed by using the B3P86 hybrid functional. ${ }^{[26]}$ The large all-electron $6-311++\mathrm{G}(3 \mathrm{df}, 3 \mathrm{pd})$ basis set was employed for $\mathrm{C}, \mathrm{H}, \mathrm{N}$, and $\mathrm{O}$ atoms, while the large all-electron WTBS ("Well-Tempered Basis Set" of Huzinaga and co-workers ${ }^{[27]}$ basis set was used for the Ru atoms. Structure optimizations and mechanistic DFT calculations were carried out using the hybrid B3LYP functional. ${ }^{[28]}$ The LanL2DZ basis set, with relativistic effective core potentials, was used for the Ru atoms. ${ }^{[29]}$ The basis set used for the remaining atoms was the 6$31 \mathrm{G}(\mathrm{d}, \mathrm{p})$. All optimized stationary points were confirmed as energy minima (all positive eigenvalues) or transition states (one imaginary eigenvalue) by analytical calculation of frequencies. IRC calculations were used to verify that the transition states found were correct saddle points connecting the proposed minima. All energies given in this contribution are potential energies calculated in gas phase. All mechanistic calculations were carried out with the Gaussian09 program package. ${ }^{[23]}$ Cartesian coordinates for the atoms of all optimized structures are given in the Supporting Information.

\section{Acknowledgements}

This work has been supported by the Spanish MICINN-FEDER grants CTQ201014933, MAT2010-15094, CSD2006-00015 and DELACIERVA-09-05, the European Union Marie Curie action FP7-2010-RG-268329 and a Severo Ochoa fellowship from Principado de Asturias (to V.P.).

[1] For representative examples, see: a) M. A. Esteruelas, F. J. FernándezÁlvarez, M. Oliván, E. Oñate, Organometallics 2009, 28, 2276-2284; b) S. Conejero, J. López-Serrano, M. Paneque, A. Petronilho, M. L. Poveda, F. Vattier, E. Álvarez, E. Carmona, Chem. Eur. J. 2012, 18, 4622-4664; c) M. Roselló-Merino, J. Díez, S. Conejero, Chem. Commun. 2010, 46, 9247-9249.

[2] For recent reviews, see: a) O. Schuster, L. Yang, H. G. Raubenheimer, M. Albrecht, Chem. Rev. 2009, 109, 3445-3478; b) H. G. Raubenheimer, S. Cronje, Dalton Trans. 2008, 1265-1272.

[3] a) A. Magriz, S. Gómez-Bujedo, E. Álvarez, R. Fernández, J. M. Lassaletta, Organometallics 2010, 29, 5941-5945; b) B. Hildebrandt, G. Reiß, C. Ganter, J. Organomet. Chem. 2010, 695, 474-477; c) B. Crociani, F. Dibianca, R. Bertani, C. B. Castellani, Inorg. Chim. Acta 1985, 101, 161-169; d) B. Crociani, F. Dibianca, A. Giovenco, A. Scrivanti, J. Organomet. Chem. 1985, 291, 259-272.

[4] a) J. A. Cabeza, I. del Río, E. Pérez-Carreño, M. G. Sánchez-Vega, D. Vázquez-García, Angew. Chem. 2009, 121, 563-566; Angew. Chem. Int. Ed. 2009, 48, 555-558; b) J. A. Cabeza, I. del Río, E. Pérez-Carreño, M. G. Sánchez-Vega, D. Vázquez-García, Organometallics 2010, 29, 4464-4471.

[5] For representative examples, see: a) J. Sung, K. S. Huang, T. J. Lai, Y. Y. Chen, C. Y. Lin, A. Yeh, D. Wu, Inorg. Chem. 2008, 47, 11361-11366; b) S. I. Gorelsky, A. B. Ilyukhin, P. V. Kholin, V. Y. Kotov, B. V. Lokshin, N. V. Sapoletova, Inorg. Chim. Acta 2007, 360, 2573-2582; c) A. B. P. Lever, Can. J. Chem. 2004, 82, 1102-1111; d) D. Adam, B. Herrschaft, H. Hartl, Z. Naturforsch., B 1991, 46, 738-746; e) J. F. Wishart, A. Bino, H. Taube,
Inorg. Chem. 1986, 25, 3318-3321; f) H. D. Wohlers, K. D. Van Tassel, B. A Bowerman, J. D. Petersen, Inorg. Chem. 1980, 19, 2837-2838; g) R. H. Magnuson, H. Taube, J. Am. Chem. Soc. 1975, 97, 5129-5136.

[6] See, for example: a) I. Ando, K. Nishihara, K. Ujimoto, H. Kurihara, Inorg. Chim. Acta 2003, 346, 19-24; b) S. Berger, A. Klein, W. Kaim, J. Fiedler, Inorg. Chem. 1998, 37, 5664-5671; c) P. A. Lay, R. H. Magnuson, H. Taube, Inorg. Chem. 1988, 27, 2848-2853; d) C. Creutz, M. H. Chou, Inorg. Chem. 1987, 26, 2995-3000.

[7] J. A. Cabeza, I. del Río, M. C. Goite, E. Pérez-Carreño, V. Pruneda, Chem. Eur. J. 2009, 15, 7339-7349.

[8] J. A. Cabeza, I. del Río, E. Pérez-Carreño, V. Pruneda, Organometallics 2011, $30,1145-1156$.

[9] J. A. Cabeza, P. García-Álvarez, E. Pérez-Carreño, V. Pruneda, Chem. Eur. J. 2013, 19, 3426-3436

[10] J. A. Cabeza, I. del Río, E. Pérez-Carreño, V. Pruneda, Chem. Eur. J. 2010, $16,5425-5436$.

[11] A small part of this work has been communicated in a preliminary form: J. A. Cabeza, P. García-Álvarez, E. Pérez-Carreño, V. Pruneda, Dalton Trans. 2012, 41, 4313-4315.

[12] For kinetic studies on deprotonation reactions of 2-methylpyrazinium cations, see: a) T. W. S. Lee, R. Stewart, Can. J. Chem. 1986, 64, 1085-1089; b) K Nagarajan, T. W. S. Lee, R. R. Perkins, R. Stewart, Can. J. Chem. 1986, 64, 1090-1095.

[13] See, for example: D. McHattie, R. Buchan, M. Fraser, P. V. S. K. T. Lin, Heterocycles 1992, 34, 1759-1771 and references therein.

[14] A. E. Reed, L. A. Curtis, F. Weinhold, Chem. Rev. 1988, 88, 899-926.

[15] a) R. F. W. Bader, Atoms in Molecules: A Quantum Theory, Oxford University Press, Oxford, UK, 1990; b) P. Popelier, Atoms in Molecules: An Introduction, Prentice Hall, Harlow, UK, 2000; c) The Quantum Theory of Atoms in Molecules (Eds: C. F. Matta, R. J. Boyd), Wiley-VCH, Weinheim, Germany, 2007; d) Modern Charge Density Analysis (Eds: C. Gatti, P. Macchi), Springer, Heidelberg, Germany, 2012; e) Electron Density and Chemical Bonding I and II (Ed.: D. Stalke), in Structure and Bonding, vol. 146 and 147, Springer, Heidelberg, Germany, 2012.

[16] See, for example: a) R. F. W. Bader, J. Phys. Chem. A 1998, 102, 7314 7323; b) F. Cortés-Guzmán, R. F. W. Bader, Coord. Chem. Rev. 2005, 249 , 633-662; c) T. S. Koritsanszky, P. Coppens, Chem. Rev. 2001, 101, 15831627; d) Macchi, P.; Sironi, A. Coord. Chem. Rev. 2003, 238, 383-412; e) P. Coppens, B. B. Iversen, F. K. Larsen, Coord. Chem. Rev. 2005, 249, 179-195. (f) Y. Ling, Y. Zhang, Ann. Rep. Comput. Chem. 2010, 6, 65-77; (g) P. Macchi, Angew. Chem. 2009, 121, 5905-5907; Angew. Chem., Int. Ed. 2009, $48,5793-5795$.

[17] S. Parkin, B. Moezzi, H. Hope, J. Appl. Cryst. 1995, 28, 53-56.

[18] CrysAlisPro RED, version 1.171.33.41. Oxford Diffraction Ltd., Oxford, UK, 2009.

[19] P. T. Beurskens, G. Beurskens, R. de Gelder, J. M. M Smits, S. GarcíaGranda, R. O. Gould, The DIRDIF Program System, version 2008.3. Crystallography Laboratory, University of Nijmegen, Nijmegen, The Netherlands, 2008

[20] G. M. Sheldrick, Acta Crystallogr. 2008, A64, 112-122.

[21] A. G. Orpen, J. Chem. Soc., Dalton Trans. 1980, 2509-2516.

[22] L. J. Farrugia, J. Appl. Crystallogr. 1999, 32, 837-838.

[23] M. J. Frisch, G. W. Trucks, H. B. Schlegel, G. E. Scuseria, M. A. Robb, J. R. Cheeseman, G. Scalmani, V. Barone, B. Mennucci, G. A. Petersson, H. Nakatsuji, M. Caricato, X. Li, H. P. Hratchian, A. F. Izmaylov, J. Bloino, G. Zheng, J. L. Sonnenberg, M. Hada, M. Ehara, K. Toyota, R. Fukuda, J. Hasegawa, M. Ishida, T. Nakajima, Y. Honda, O. Kitao, H. Nakai, T. Vreven, J. A. Montgomery, Jr., J. E. Peralta, F. Ogliaro, M. Bearpark, J. J. Heyd, E. Brothers, K. N. Kudin, V. N. Staroverov, T. Keith, R. Kobayashi, J. Normand, K. Raghavachari, A. Rendell, J. C. Burant, S. S. Iyengar, J. Tomasi, M. Cossi, N. Rega, J. M. Millam, M. Klene, J. E. Knox, J. B. Cross, V. Bakken, C. Adamo, J. Jaramillo, R. Gomperts, R. E. Stratmann, O. Yazyev, A. J. Austin, R. Cammi, C. Pomelli, J. W. Ochterski, R. L. Martin, K. Morokuma, V. G. Zakrzewski, G. A. Voth, P. Salvador, J. J. Dannenberg, S. Dapprich, A. D. Daniels, O. Farkas, J. B. Foresman, J. V. Ortiz, J. Cioslowski, D. J. Fox, GAUSSIAN 09, revision B.01. Gaussian, Inc., Wallingford, Connecticut, 2010. 
[24] a) A. E. Reed, R. B. Weinstock, F. Weinhold, J. Chem. Phys. 1985, 83, 735746; b) A. E. Reed, L. A. Curtis, F. Weinhold, Chem. Rev. 1988, 88, 899-926.

[25] F. Biegler-König, J. Schönbohm, J. Comput. Chem. 2002, 23, 1489-1494.

[26] a) J. P. Perdew, Phys. Rev. B 1986, 33, 8822-8824.; b) A. D. Becke, J. Chem. Phys. 1993, 98, 5648-5652.

[27] a) S. Huzinaga, B. Miguel. Chem. Phys. Lett. 1990, 175, 289-291; b) S. Huzinaga, M. Klobukowski, Chem. Phys. Lett. 1993, 212, 260-264.
[28] C. Lee, W. Yang, R. G. Parr, Phys. Rev. B 1988, 37, 785-789.

[29] P. J. Hay, W. R. Wadt, J. Chem. Phys. 1985, 82, 299-310.

Received: ((will be filled in by the editorial staff)) Published online: ((will be filled in by the editorial staff)) 
Entry for the Table of Contents

\section{C-H Deprotonation}

J. A. Cabeza, * J. M. Fernández-Colinas,

P. García-Álvarez, E. Pérez-Carreño,

V. Pruneda, J. F. Van der Maelen

Page - Page

Deprotonation of C-Alkyl Groups of Cationic Triruthenium Clusters

Containing Cyclometalated C-

Alkylpyrazinium Ligands:

Experimental and Computational

Studies

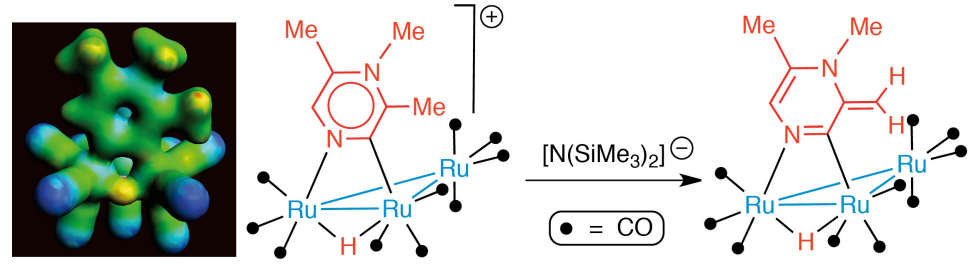

Reactive alkyl groups: On

through charge-controlled processes, triruthenium clusters, the $\mathrm{C}$-methyl to give neutral products that contain or C-ethyl groups of N,Cdimetalated $\mathrm{C}$-alkylpyrazinium ligands can be selectively a C-alkylidene group on the heterocyclic ring. DFT and QTAIM calculations have shed light on the regioselectivity of these reactions. 